\title{
Demonstration of a high power broadband mm-wave gyro-TWA
}

\author{
Wenlong He, Liang Zhang, Craig R. Donaldson, Adrian W. Cross, and Alan D. R. Phelps \\ Department of Physics, SUPA, University of Strathclyde, \\ Glasgow G4 0NG, Scotland, UK. \\ w.he@strath.ac.uk
}

\begin{abstract}
Design and experimental results of a broadband, high power, millimetre-wave gyrotron traveling wave amplifier (gyro-TWA) operating in the 75-110 GHz frequency band and based on a helically corrugated interaction region (HCIR) and cusp electron beam source are presented. The second harmonic cyclotron mode of the electron beam was used to match the dispersion of an eigenwave in the HCIR, achieving energy transfer from the electrons to waves over a large frequency range. The gyro-TWA was measured to generate a maximum power of a few $\mathrm{kWs}$ with an unsaturated gain of 36-38 $\mathrm{dB}$ in the driving frequency band of 91-96.5 GHz.
\end{abstract}

Keywords-gyrotron traveling wave amplifier, gyro-TWA, gyrodevice, gyrotron amplifier

\section{INTRODUCTION}

Gyro-devices are coherent microwave radiation sources based on the cyclotron resonance maser instability [1]. The gyrotron traveling wave amplifier (gyro-TWA) has promising applications in telecommunications, RADAR, plasma diagnostics, electron paramagnetic resonance (EPR) and so on due to its high power and broadband capabilities [2-4]. GyroTWAs, using HCIR structures [5] and operating at mm-wave and terahertz frequency ranges are under development at the University of Strathclyde. A gyro-TWA operating at 90-100 $\mathrm{GHz}$ was designed to achieve $5 \mathrm{~kW}$ with an amplification gain of $\sim 37 \mathrm{~dB}$ using a $55 \mathrm{keV}, \sim 1.5 \mathrm{~A}$ axis-encircling electron beam. Another gyro-TWA operating at higher frequency, at a centre frequency of $372 \mathrm{GHz}$, is also being designed for EPR applications.

\section{SET UP AND RESULTS}

A schematic drawing of the experimental setup is shown in Fig. 1.

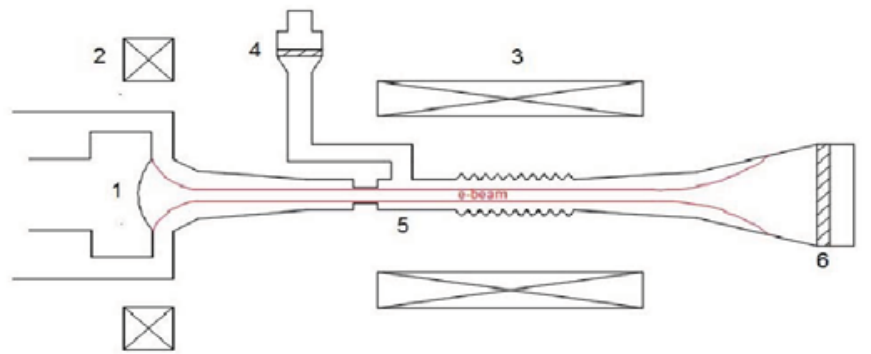

Fig. 1. The schematic of a gyro-TWA. (1) electron gun, $(2,3)$ coil system, (4) pillbox window, (5) input coupler, (6) output window.
The microwave seed signal was coupled into the ultra-high vacuum system through a broadband (88-104 GHz), high transmission $(-0.6 \mathrm{~dB})$ pillbox microwave window. A sidewall coupler $[6,7]$ with a T-junction structure [8] was used to convert the $\mathrm{TE}_{10}$ mode in rectangular waveguide into the $\mathrm{TE}_{11}$ mode in the circular waveguide. An optimized broadband Bragg reflector was used at one port of the T-junction to allow the electron beam to pass without interception and at the same time to minimize any millimetre-waves propagating into the electron gun region. A polariser was used after the millimetrewave coupler to convert the linearly polarised $\mathrm{TE}_{11}$ wave into a circularly polarised one, to ensure all the drive power is in the correct polarisation for interaction with the HCIR to produce the operating eigenwave that is optimum for the gyroTWA.

After the input millimetre-wave entered the helical waveguide was amplified in the interaction region, producing higher power radiation which could be converted into a Gaussian beam by using a mode-converting horn $[9,10]$. In this experiment a smoothly profiled horn [11] as shown in Fig. 2 was optimized to achieve a high Gaussian content $(>98 \%)$ with negligible reflection $(-37 \mathrm{~dB})$ over the operating bandwidth.

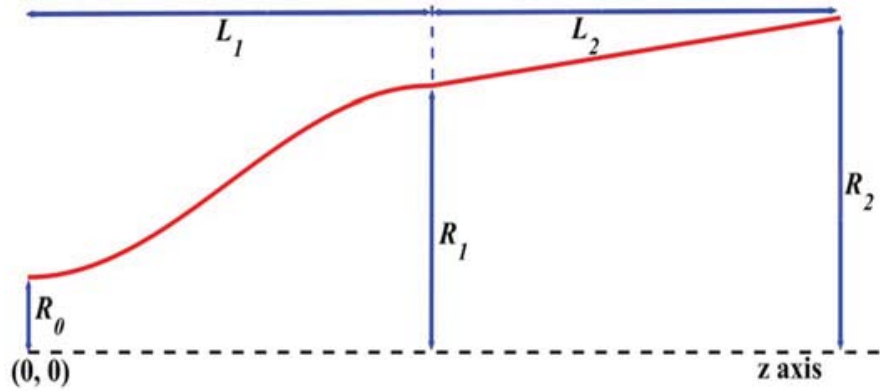

Fig. 1 The profile of the output horn used in the experiment.

The measured far-field radiation patterns using a W-band vector network analyzer (VNA) (Anritsu ME7808) showed good agreement with the simulated results. The wave was coupled out of the system through a multiple-disc window [12]. The reflection of the multiple-disc window was measured to be better than $-33 \mathrm{~dB}$ with negligible power absorption (Fig. 3). 


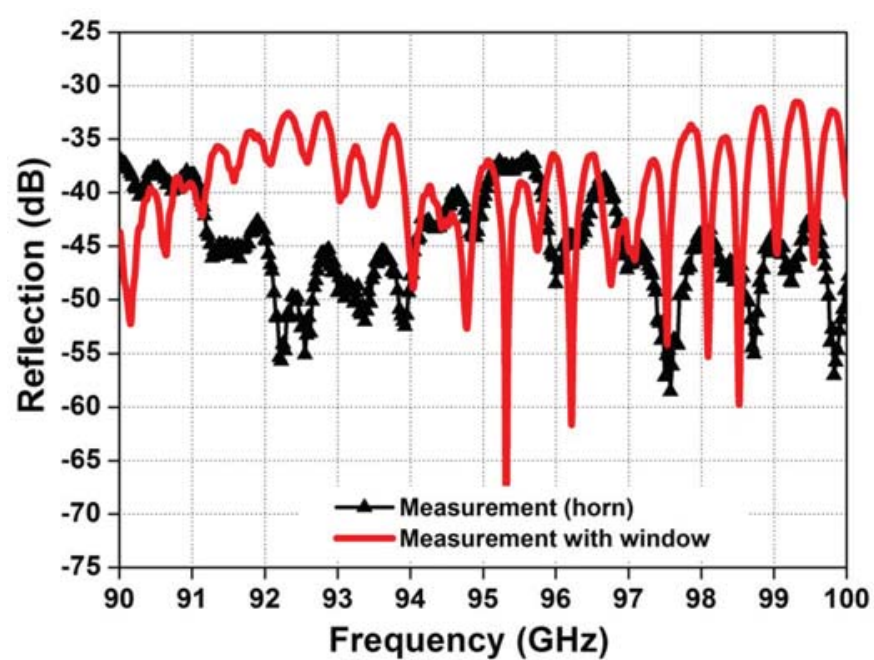

Fig. 2 The measured reflection of the smoothly profiled horn with and without the addition of a multilayer microwave window.

The VNA was used to measure the millimetre-wave properties, such as Ohmic loss and scattering parameters, of each individual component both separately and when assembled together to form the overall gyro-TWA.

A double-Blumlein pulse forming network made from a high voltage cable and a spark-gap switch was used to provide the accelerating field for the electron beam. The electron accelerating potential was measured using a resistive voltage divider, while electron current, typically $1.5 \mathrm{~A}$ at operating temperature, was measured using a current transformer. The beam current was measured in the cavity using a Faraday cup, inserted into the beam tube. This beam current of $1.5 \mathrm{~A}$ was measured at the normal operating cathode temperature, although it was variable by adjusting the heating power applied to the cathode

\section{RESULTS}

The output microwave radiation signal (detected by two crystal detectors situated inside screened boxes) and its farfield mode pattern were measured and are shown in Fig. 4 and Fig. 5.

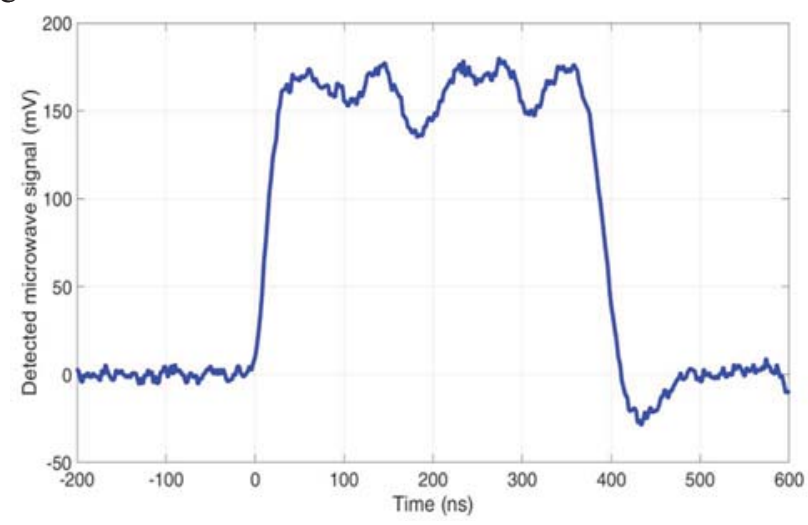

Fig. 4 Measured microwave signal of the broadband W-band gyro-TWA.

The sensitivity of the crystal detector at different input power levels was carefully calibrated before the gyro-TWA experiment. Then the detector was positioned at a far enough position away from the output window of the gyro-TWA to avoid any possible reflection from the screened box itself. The transmission loss of the whole gyro-TWA was carefully measured by a W-band Vector Network Analyzer. From the measurement it was found that $1.5 \mathrm{~W}$ at the input of the gyroTWA was attenuated to $\sim 0.5 \mathrm{~W}$ at the output window of the gyro-TWA. From the detector outputs in the "cold" and "hot" (without and with electron beam operating in amplification mode) experimental conditions, the amplification gain and the output power of the gyro-TWA at different input levels were measured. The experimental results of the output power and amplification gain as a function of driving frequency were also measured.

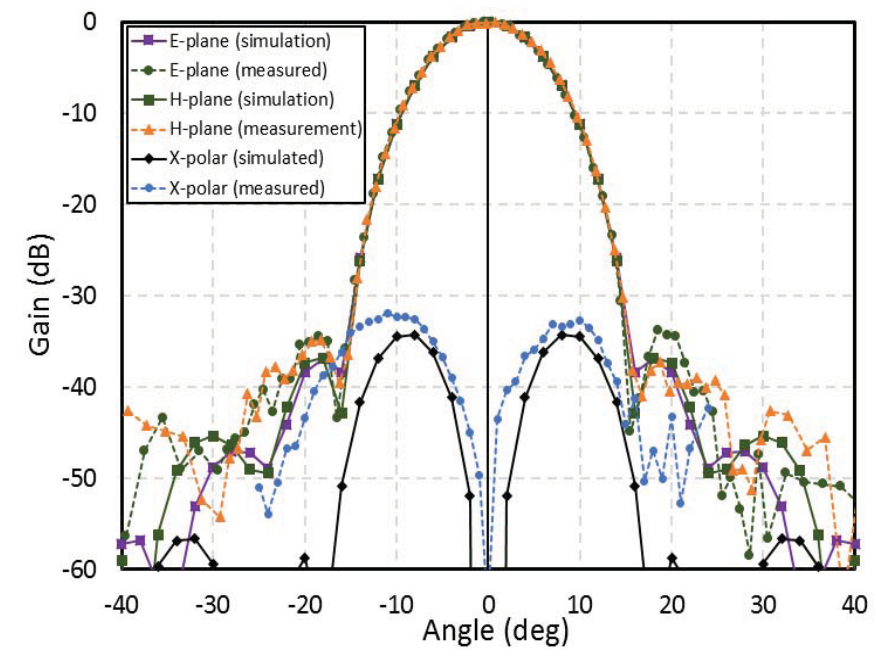

Fig.5 Measured far-field radiation pattern of the broadband W-band gyro-TWA.

The high power, broadband W-band gyro-TWA was experimentally studied and the measured results were in good agreement with theory and numerical simulations. In the Wband gyro-TWA experiment, stable amplification over the frequency range of $90-96.5 \mathrm{GHz}$ was achieved driven by the axis-encircling electron beam with a velocity alpha value of $\sim 1$. The maximum gain was measured to be $38 \mathrm{~dB}$ at $94 \mathrm{GHz}$ with a maximum input power of $\sim 0.5 \mathrm{~W}$, which gives a maximum output power of $\sim 3.4 \mathrm{~kW}$. The output at higher input power levels and frequencies above $96.5 \mathrm{GHz}$ were not measured due to the lack of an input signal. The results were in good agreement with the simulated output power and frequency bandwidth of 90-100 GHz.

\section{CONCLUSIONS}

The gyro-TWA was proved to be zero-drive stable with an output power of $\sim 3.4 \mathrm{~kW}$ and $-3 \mathrm{~dB}$ bandwidth of over 5.5 $\mathrm{GHz}$ in a pure Gaussian output mode. From the simulation this experiment could be scaled up to operate in the higher terahertz frequency range. A gyro-TWA operating at $372 \mathrm{GHz}$ has been designed to generate $\sim 500 \mathrm{~W}$ output power over a frequency bandwidth of over $5 \%$. 


\section{ACKNOWLEDGEMENTS}

The authors would like to thank EPSRC and STFC UK for supporting this work and Dr. P. Huggard, Mr M. Beardsley and Mr. P. Hiscock of the Millimetre-Wave Technology Group at the STFC Rutherford Appleton Laboratory, UK for the construction of the HCIR.

\section{REFERENCES}

[1] W. He, C. R. Donaldson, L. Zhang, K. Ronald, P. McElhinney, and A.W. Cross, "High power wideband gyrotron backward wave oscillator operating towards the terahertz region," Phys. Rev. Lett., vol. 110, no. 16, 165101, April 2013.

[2] G. G. Denisov, V. L. Bratman, A. W. Cross, W. He, A. D. R. Phelps, K. Ronald, S. V. Samsonov, and C. G. Whyte, "Gyrotron traveling wave amplifier with a helical interaction waveguide," Phys. Rev. Lett., vol. 81, no. 25 , pp. 5680-5683, Dec. 1998.

[3] V. L. Bratman, A. W. Cross, G. G. Denisov, W. He, A. D. R. Phelps, K. Ronald, S. V. Samsonov, C. G. Whyte, and A. R. Young, "High-gain wide-band gyrotron traveling wave amplifier with a helically corrugated waveguide," Phys. Rev. Lett., vol. 84, no. 12, pp. 2746-2749, March 2000

[4] A. W. Cross, W. He, A. D. R. Phelps, K. Ronald, C. G. Whyte, A. R. Young, C. W. Robertson, E. G. Rafferty, and J. Thomson, "Helically corrugated waveguide gyrotron traveling wave amplifier using a thermionic cathode electron gun," Appl. Phys. Lett., vol. 90, no. 25, 253501, June 2007.

[5] L. Zhang, W. L. He, K. Ronald, A. D. R. Phelps, C. G. Whyte, C. W. Robertson, A. R. Young, C. R. Donaldson, and A. W. Cross, "Multi-
Mode Coupling Wave Theory for Helically Corrugated Waveguide," IEEE Trans. Microw. Theory Techn., vol 60, no. 1, pp. 1-7, Jan. 2012.

[6] J. R. Garner, L. Zhang, C. R. Donaldson, A. W. Cross, and W. He, "Design Study of a Fundamental Mode Input Coupler for a $372-\mathrm{GHz}$ Gyro-TWA I: Rectangular-to-Circular Coupling Methods," IEEE Trans. Electron Devices, vol. 63, no. 1, pp. 497-503, Jan. 2016.

[7] J. R. Garner, L. Zhang, C. R. Donaldson, A. W. Cross, and W. He, "Design Study of a 372-GHz Higher Order Mode Input Coupler," IEEE Trans. Electron Devices, vol. 63, no. 8, pp. 3284-3289, Aug. 2016.

[8] L. Zhang, W. He, C. R. Donaldson, J. R. Garner, P. McElhinney, and A. W. Cross, " Design and Measurement of a Broadband Sidewall Coupler for a W-Band Gyro-TWA," IEEE Trans. Microw. Theory Techn. vol. 63, pp. 3183-3190, 2015.

[9] P. McElhinney, C.R. Donaldson, J. E. McKay, L. Zhang, D. A. Robertson, R. I. Hunter, G. M. Smith, W. He, and A.W. Cross, "An output coupler for a W-band high power wideband gyro-amplifier," IEEE Trans. Electron Devices, vol. 64, no. 4, pp. 1763-1766, 2017.

[10] P. McElhinney, C. R. Donaldson, L. Zhang and W. He, "A High Directivity Broadband Corrugated Horn for W-band Gyro-devices," IEEE Trans on Antennas Propag., 61 (3), pp. 1453-1456, 2013.

[11] L. Zhang, W. He, C. R. Donaldson, G. M. Smith, D. A. Robertson, R. I. Hunter, and A. W. Cross, "Optimization and Measurement of a Smoothly Profiled Horn for a W-Band Gyro-TWA," IEEE Trans. Electron Devices, vol. 64, no. 6, pp. 2665-2669, 2017.

[12] C. R. Donaldson, P. McElhinney, L. Zhang, and W. He, "Wide-band $\mathrm{HE}_{11}$ mode terahertz wave windows for gyro-amplifiers," IEEE Trans. THz Sci. Technol., vol. 6, no. 1, pp. 108-112, Jan. 2016. 